\title{
THE DISCHARGE OF STEAM THROUGH NOZZLES.
}

By Dr. WM. E. FISHER, of the University of Birmingham.

[Selected for Publication with Discussion in writing.]

When steam expands in a nozzle, if the internal energy given up is entirely used in adding to the kinetic energy of the stream, there is, for a given initial pressure, one lower pressure at which the product of the velocity and density of the stream is a maximum. The value of this "critical pressure" depends upon the law of expansion; for the adiabatic expansion of steam, it is frequently taken as 0.58 of the initial pressure. It is obvious that at this stage the mass flow through a passage of given area is greatest. So long as the energy equation is satisfied, the conditions in the nozzle will be stable when they lead to a maximum discharge. For low back-pressures the critical pressure therefore in general prevails at the smallest cross-section of a nozzle. If the backpressure is raised so that the critical pressure cannot be reached, the discharge should fall away; if the back-pressure is lowered, the conditions between the entrance and throat of the nozzle are not altered and the discharge should remain constant.

[Tне I.Месн.E.] 
The experiments to be described had for their object the measurement of the actual discharge from nozzles when the supply pressure is kept constant and the back-pressure varied. Throughout the experiments slightly superheated steam was employed, so that there was no uncertainty about the quality; in most cases the steam was taken from a boiler with internal superheater, and was very constant in temperature.

Arrangement of Apparatus.-This is represented in Fig. 1. The nozzle fitting, $\mathrm{N}$, was carried about 1 foot from the end of a 2 -inch

Fir. 1.-Arrangement of Apparatus.

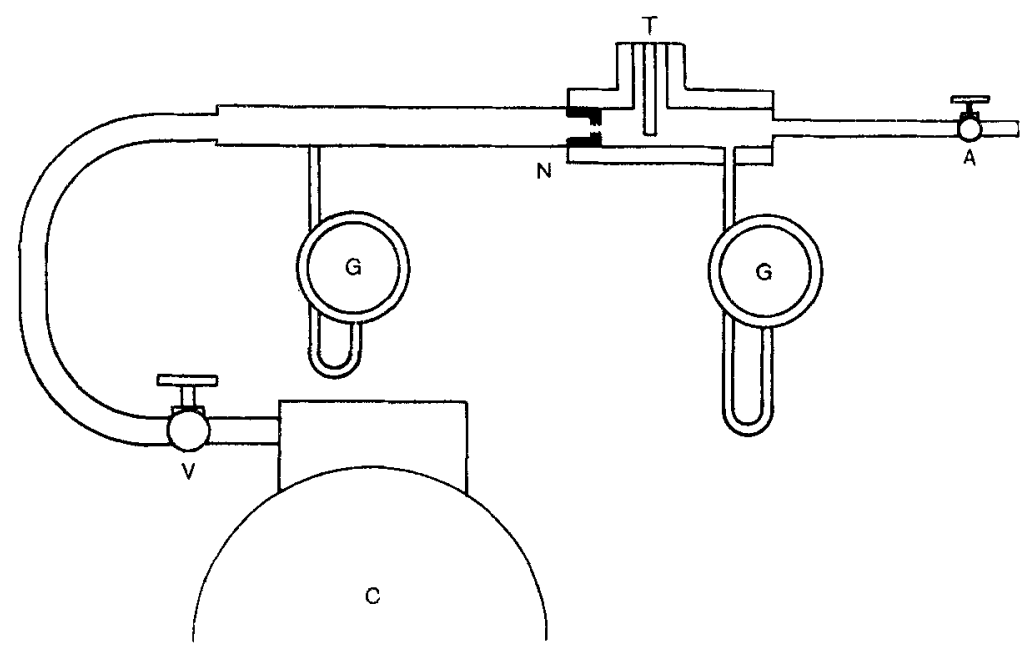

steam-pipe. Steam was supplied through a regulating valve, A. On the supply side of the nozzle was a thermometer pocket, $\mathrm{T}$, the supply chamber being well lagged to secure correct temperature readings. Pressure-gauges, G, were connected to the supply and discharge sides, at points well removed from the region of high velocity, Fig. 1. The steam, after passing a back-pressure regulating valve, $\mathrm{V}$, was led to a condenser, $C$. The gauges used were calibrated against a Crosby dead-weight tester. 
Two distinct methods of measuring the discharge were adopted. In the earlier experiments the water was allowed to drain into the condenser-pump in the usual way. The pump delivery was led into a small vessel with a discharge tube in the bottom. The object of this vessel was to damp out the effect of the pump strokes. The steady stream from the discharge tube was caught in a tank on a small weighbridge, and the time was taken when the lever floated up at 14-lb. intervals. The interval tank necessarily caused some lag between the discharge of any particular quantity of steam and its measurement, but in these tests the conditions were quite steady throughout. The supply pressure was kept constant by hand regulation, being some $20 \mathrm{lb}$. below boiler pressure; the backpressure remained constant when the valve had once been adjusted; the apparatus had in all cases been running for some time under steady conditions before any measurements were made. The discharge figures in the Tables are in most cases calculated from the mean of four determinations of the time taken to collect $42 \mathrm{lb}$. of water.

In the later experiments the air-pump was not used. The water was drained directly from the condenser into a chamber provided with a sharp-edged orifice at the bottom. The head of water above the orifice was measured by a glass gauge-tube and scale. The free surface of the water in the chamber was reduced to about 1 square inch, so that changes in the rate of flow were recorded almost instantly. With this apparatus the changes in discharge due to slight variations in the steam temperature could be instantly detected, the lag being less than that of the thermometer.

At the water-inlet to the chamber a thermometer was inserted. To determine the discharge from the gauge reading, the apparatus was tested with water at a large number of different heads and temperatures. A calibration curve was plotted having for its co-ordinates-

(1) The water temperature.

(2) The discharge divided by the square root of the head.

This curve was used to give the discharge from the temperature and head in the actual experiments. The experimental curves 
given later show that this second method of water measurement gave the more consistent results.

Nozzles and Orifices. - All these had a diameter of $\frac{1}{4}$ inch at the smallest section. Tests were made using the following, Fig. 2 :-

Frg. 2.-Nozzles and Orifices.

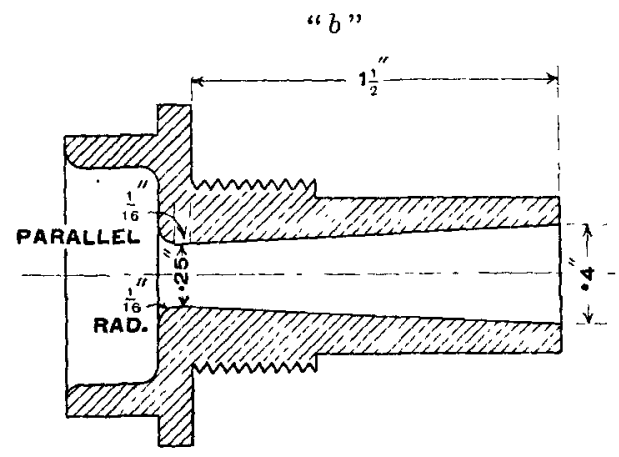

$$
\text { "c" and " } d " \text { "e" }
$$
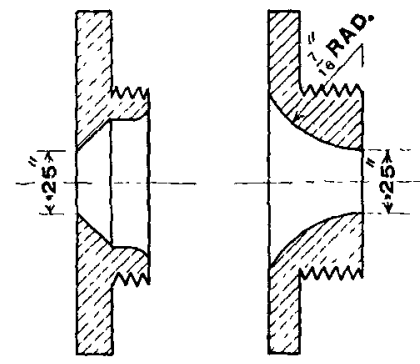

" $a "$

$$
" f "
$$
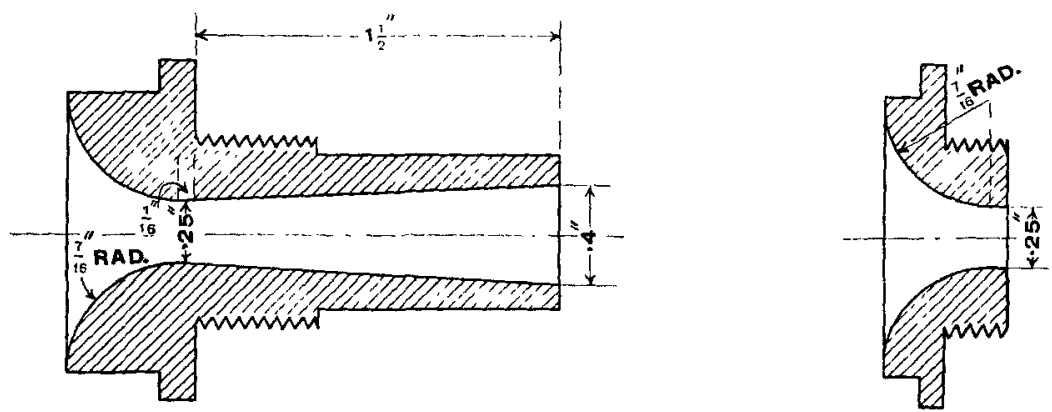

" $a . "$ This has a throat diameter of $\frac{1}{4}$ inch, the throat being parallel for $\frac{1}{16}$ inch to secure accuracy in machining. The approach curve has a radius of $\frac{7}{16}$ inch. The divergent portion is $1 \frac{1}{2}$ inch long, and has a taper of 1 in 10 on the diameter, giving a final diameter of 0.4 inch. The sizes are suited for adiabatic expansion of steam from $180 \mathrm{lb}$. per square inch abs. to $15 \mathrm{lb}$. per square inch abs. 
" $b$." This nozzle exactly resembles the previous one except that the approach is more abrupt, having a radius of about $\frac{1}{16}$ inch.

"c." A sharp-edged orifice, $\frac{1}{4}$ inch in diameter.

" $d . "$ A second sharp-edged orifice made to the same drawing as "c."

" $e$." A nozzle having an approach curve of $\frac{7}{16}$ inch radius with a final diameter of $\frac{1}{4}$ inch. No parallel or divergent part.

FIG. 3.-Nozzle " $a . " \quad$ Supply Pressure, 172 lb. per square inch abs.

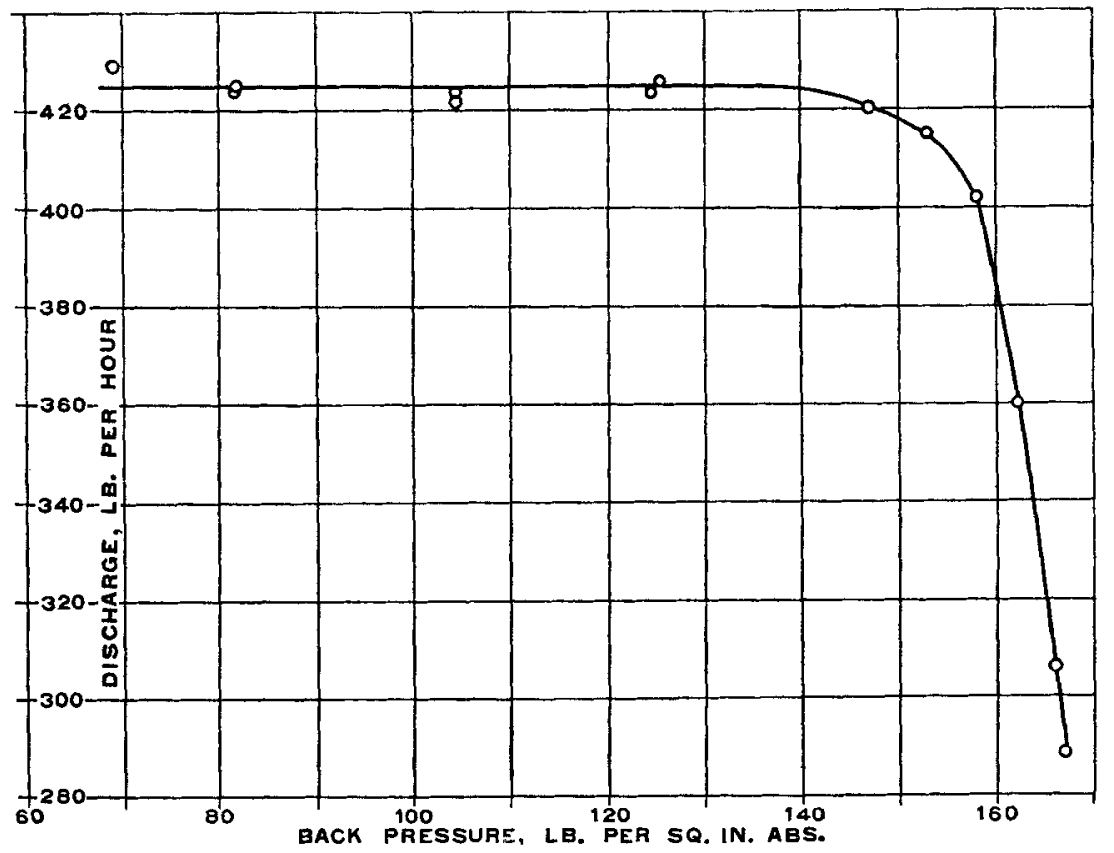

" $f$ " A nozzle similar to " $e$," but with a parallel length of $\frac{1}{16}$ inch added.

Experimental Results.-The curves, Figs. 3-11, show the discharges measured. All the experimental points are shown. The results of Figs. 3-7 were obtained by weighing; those of Figs. 8-11 by using the water-gauge and sharp-edged orifice. 
The Tables 1-9 (pages 941-945) give the figures for the discharges, and also the temperature of the steam supply. The FIg. 4.-Nozzle "a." Supply Pressure, 110 lb. per square inch abs.

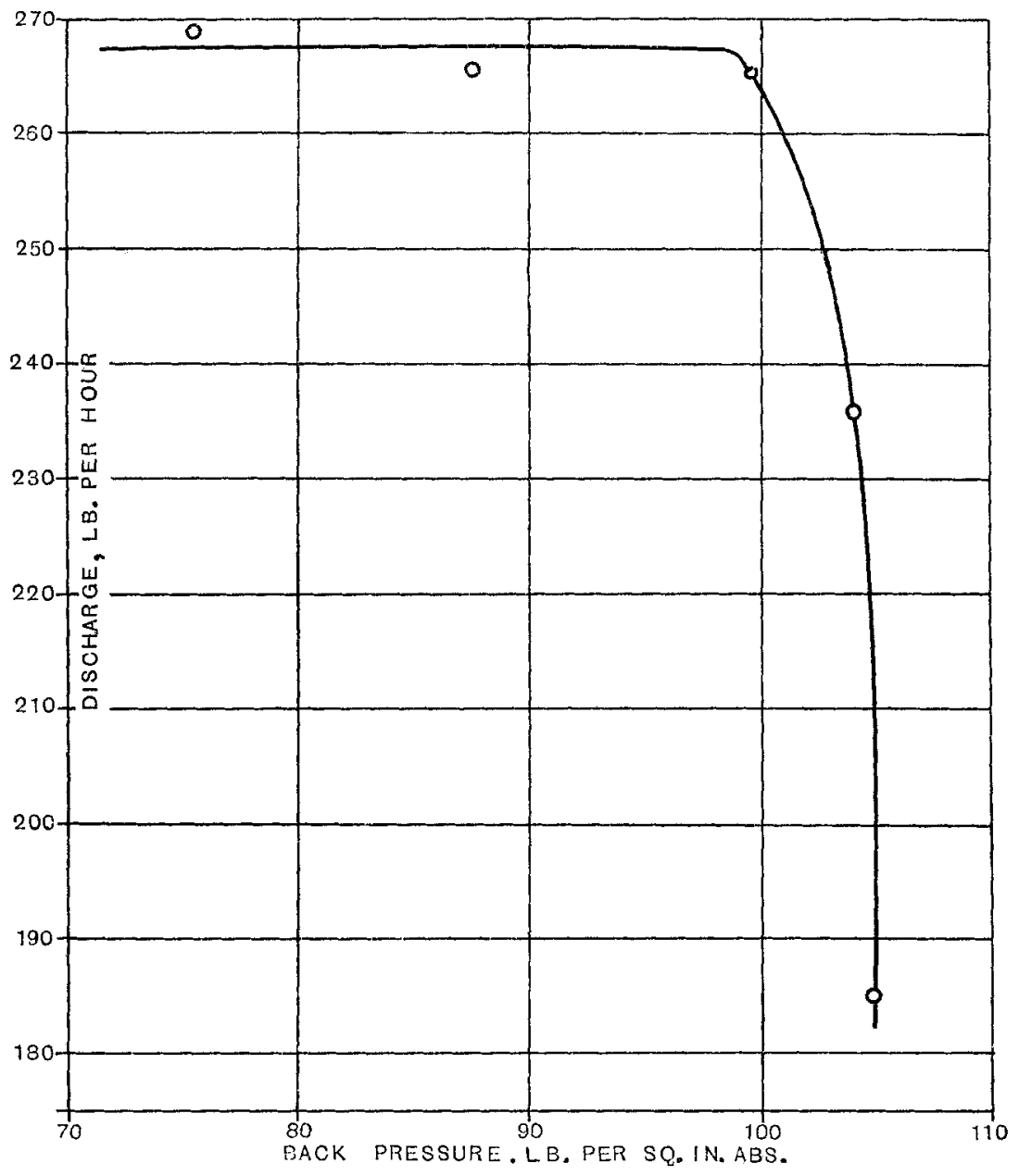

discharge becomes less when hotter steam is used. The temperature of saturation corresponding to the supply pressure is $369 \cdot 5^{\circ} \mathrm{F}$. for the high-pressure tests: 
Divergent Nozzles.-Figs. 3 and 4 and Tables 1 and 2 (page 941) show the results of tests with nozzle " $a$ " ( 1 in 10 taper outlet and $\frac{7}{16}$ inch radius approach curve). It will be seen that the discharge remained practically at its maximum value till the back-pressure was about 0.8 of the supply pressure when this was $172 \mathrm{lb}$. per

Fra. 5.-Nozzle " $b . "$ Supply Pressure, 172 lb. per square inch abs.

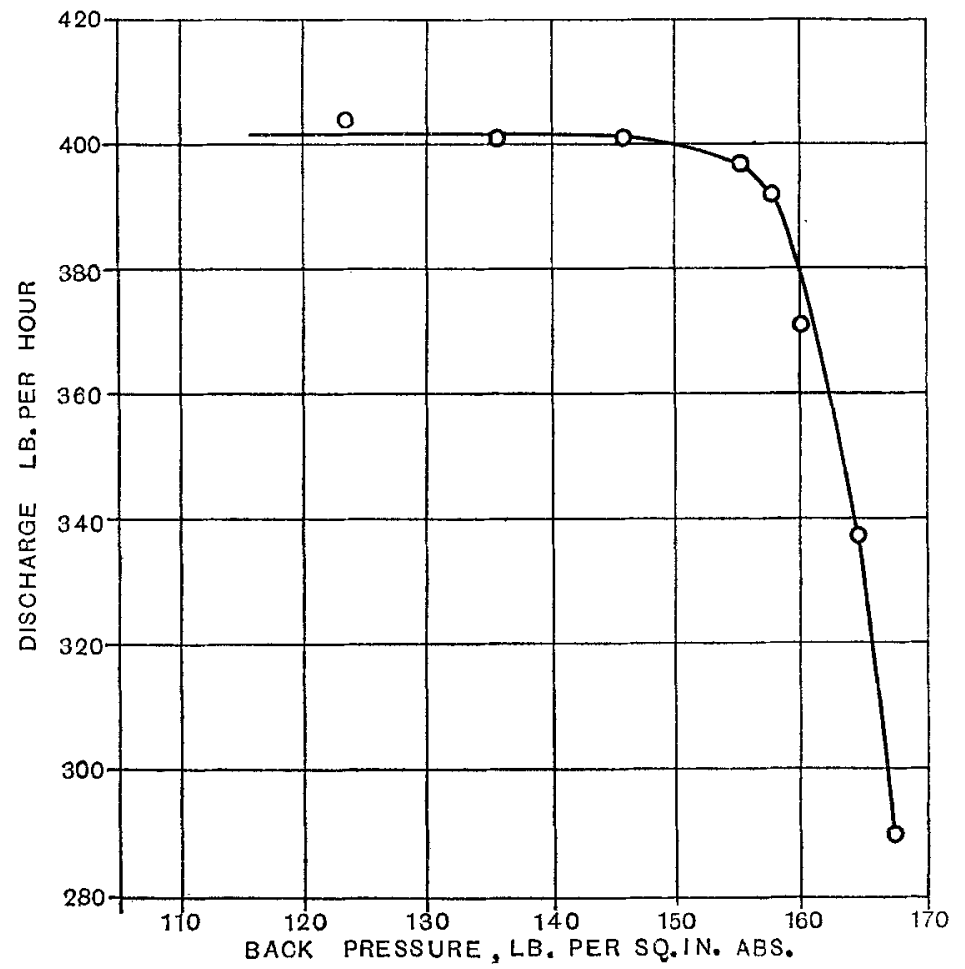

square inch abs. When the supply pressure was $110 \mathrm{lb}$. per square inch, the back-pressure was raised to 0.9 of the supply pressure before the discharge fell away to any considerable extent. Similar results were obtained with nozzle " $b$ " ( 1 in 10 taper outlet and abrupt inlet) as shown in Figs. 5 and 6 and Tables 3 and 4 (pages 941-2). 
The theoretical discharge, as calculated from the Tables of Marks and Davis, was $425 \mathrm{lb}$. per hour. This is almost exactly the measured value obtained when using the nozzle " $a . "$ The coefficient of discharge is therefore unity. For the nozzle " $b$ " the coeffieient is about $0 \cdot 95$. No sudden change in the discharge took place when the back-pressure passed through the region of the critical pressure.

FrG. 6.-Nozzle "b." Supply Pressure, 110 lb. per square inch abs.

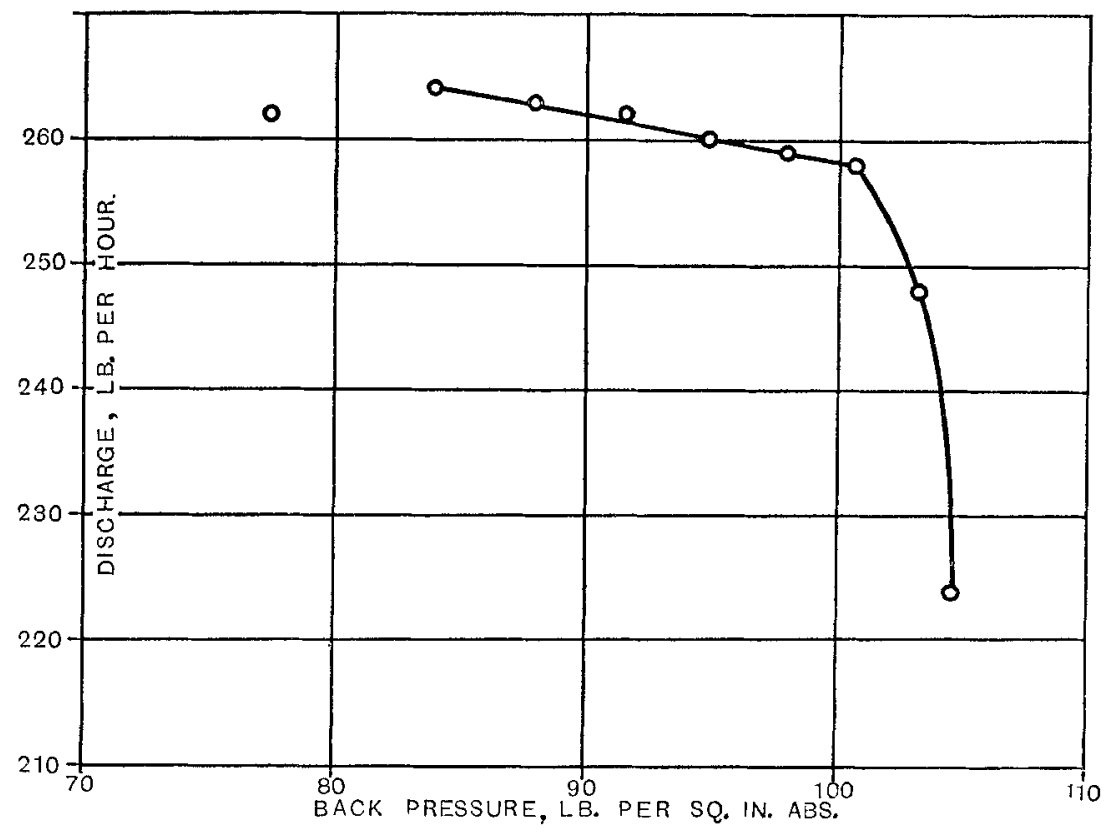

The above facts are accounted for by the observations of Stodola in his experiments using a pressure sounding tube.* When a divergent nozzle discharges against high back-pressures, the steam still tends to expand down to the critical pressure at the smallest section of the nozzle, being raised again to the back-pressure in the divergent part. So long as the critical pressure can be reached, the

* Stodola, “The Steam Turbine," Figs. 28 and 29, page 64 (1st Edition). 
conditions in the first part of the nozzle are the same for all backpressures and the discharge is the maximum. Such an action obviously takes place in nozzles " $a$ " and " $b . "$ The discharge commences to fall away rapidly only when the back-pressure is so high that the critical pressure can no longer be attained at the throat of the nozzle. These experiments therefore give no indication

FIG. 7.-Orifice "c." Supply Pressure, 172 lb. per square inch abs. First set of Experiments.

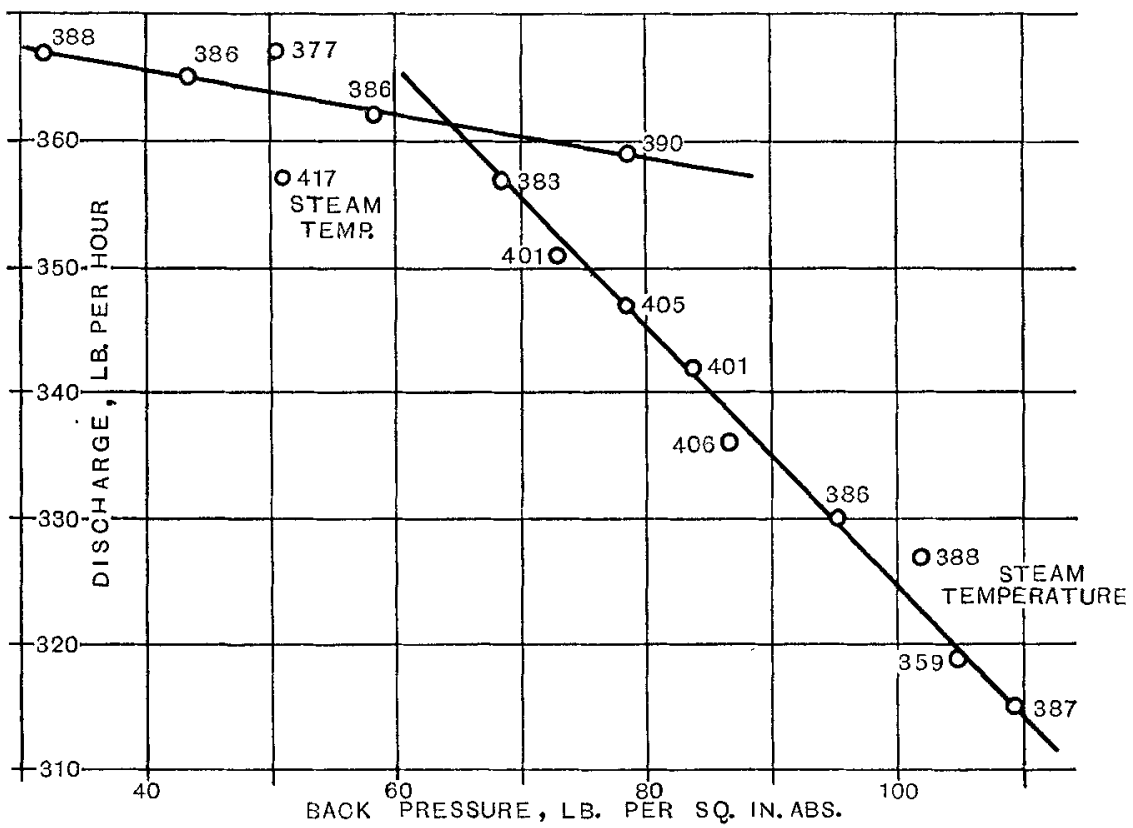

of the value of the critical pressure other than that yielded indirectly by the amount discharged.

Sharp-edged Orifices.-Figs. 7, 8 and 9 and Tables 5, 6 and 7 (pages 942-3) show the results obtained with the orifices " $c$ " and "d." Between the experiments of Figs. 7 and 8 the orifice " $c$," which was made of brass, had been used with steam at $700^{\circ} \mathrm{F}$. 
Both curves are somewhat irregular, and in Fig. 8 at any rate the measurements are not at fault, as shown by the smoothness of other curves, Figs. 9-11, obtained by the same method.

On measuring orifice " $e$ " with a microscope cathetometer it was found to be slightly oval, showing that the high temperature had

FIG. 8.-Orifice "c." Suppiy Pressure, $172 \mathrm{lb}$. per square inch abs.

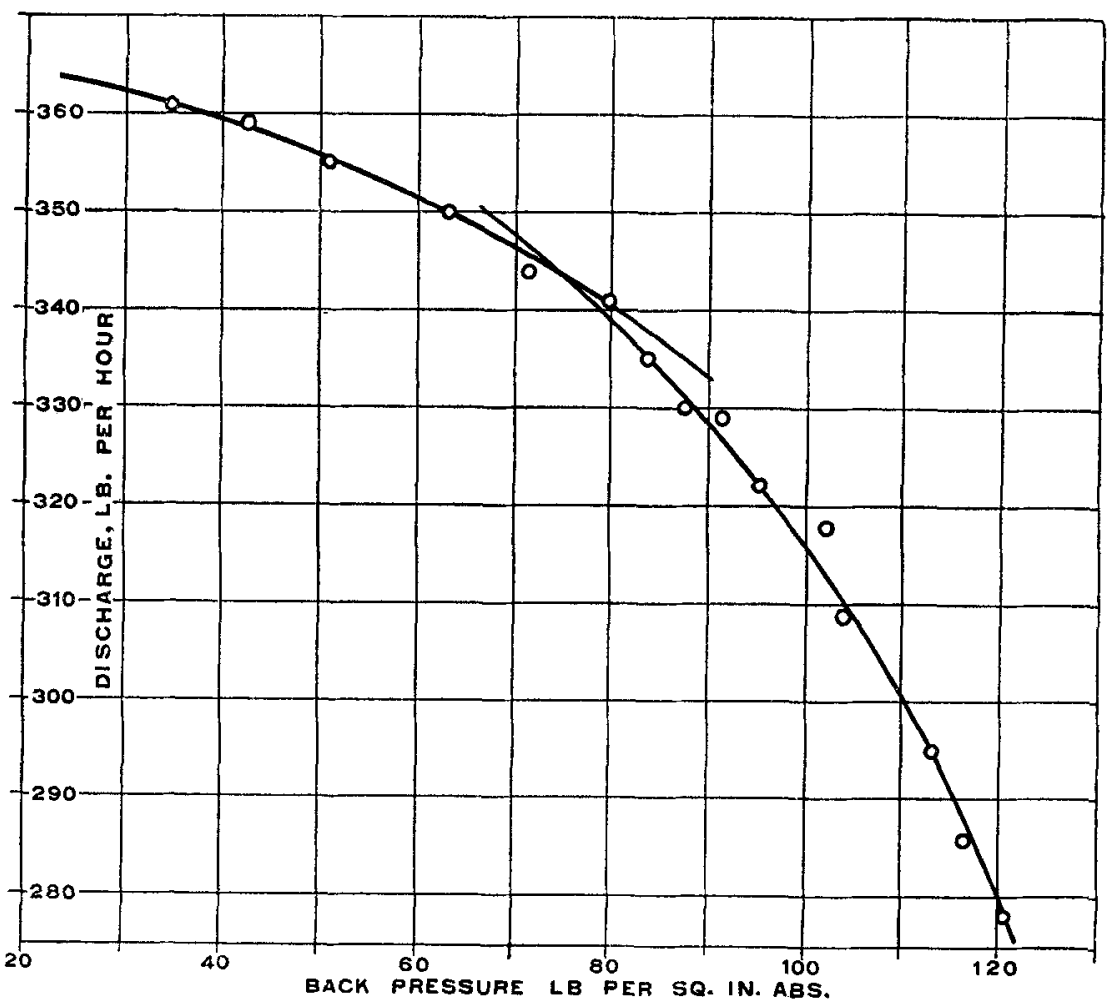

caused some change. The tool marks near the edge were still showing; there was at one place a slight wire edge. In consequence of the apparent change in the behaviour of orifice " $c$," a second one " $d$ " was made by the same workman that made the first and using the same drawing. This had no wire edge. The results 
are shown in Fig. 9. As is well known, the discharge from a sharpedged orifice varies continuously with the back-pressure, indicating that the area of the stream at its smallest section is not constant. It will be seen, however, in Figs. 7 and 9 that there is a point at which the rate of variation of the discharge changes suddenly. It seems fair to assume that this value of the back-pressure is the critical or throat pressure, since there is no chance of the overexpansion and recompression which takes place in the nozzles. In Fig. 7 the change of slope is at 0.38 of the supply pressure. In

Fig. 9.-Orifice "d." Supply Pressure, 172 lb. per square inch abs.

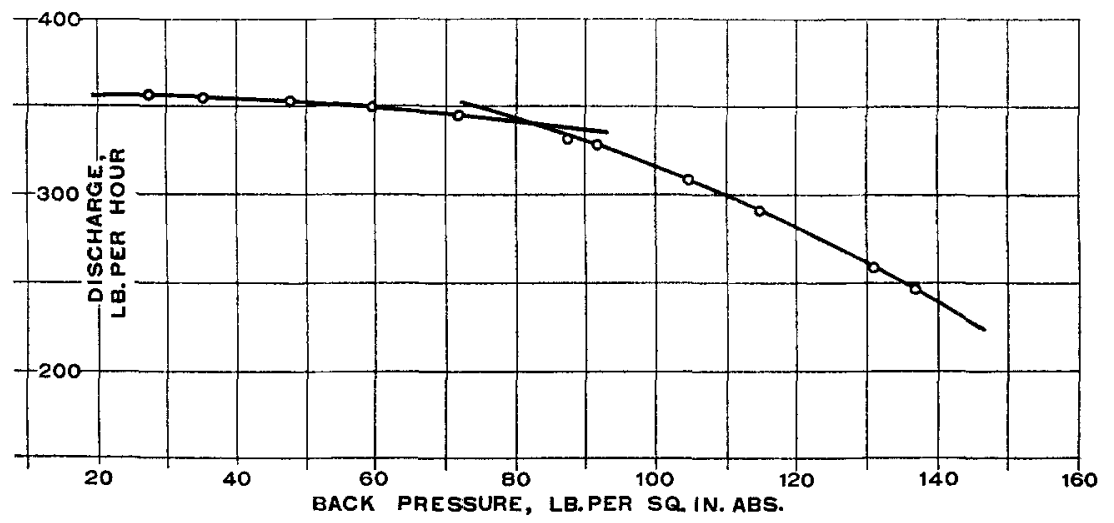

Fig. 9 (new orifice) it is at 0.465 of the supply pressure. The point in Fig. 8 is not well marked.

Supposing, for the moment, that the work of expansion is all found in the stream as kinetic energy, and that the velocity is parallel to the axis, the ratio 0.38 would indicate an expansion index of 2.6.* An increase in the index of expansion should mean an increased velocity at any particular density and an increased discharge. The maximum discharge coefficient of the sharp-edged orifice is about $0 \cdot 85$.

* See Professor Fenderson's Paper, Proceedings, I.Mech.E., 1913, page 254, for theory. 
The uncertainty of the points and the crossing of the lines of discharge on the curves, Figs. 7 and 8 , from orifice "c," as well as the apparent change in behaviour after heating, seem to indicate that the pressure distribution in the stream can be largely influenced by small changes in the nature of the edge.

Nozzles without Divergent Parts.-It has been noted that the experiments with nozzles " $a$ " and " $b$ " afforded no direct evidence as to the value of the critical pressure. To avoid the possibility of

Fia. 10.-Nozвle "e." Supply Pressure, 172 lb. per square inch abs.

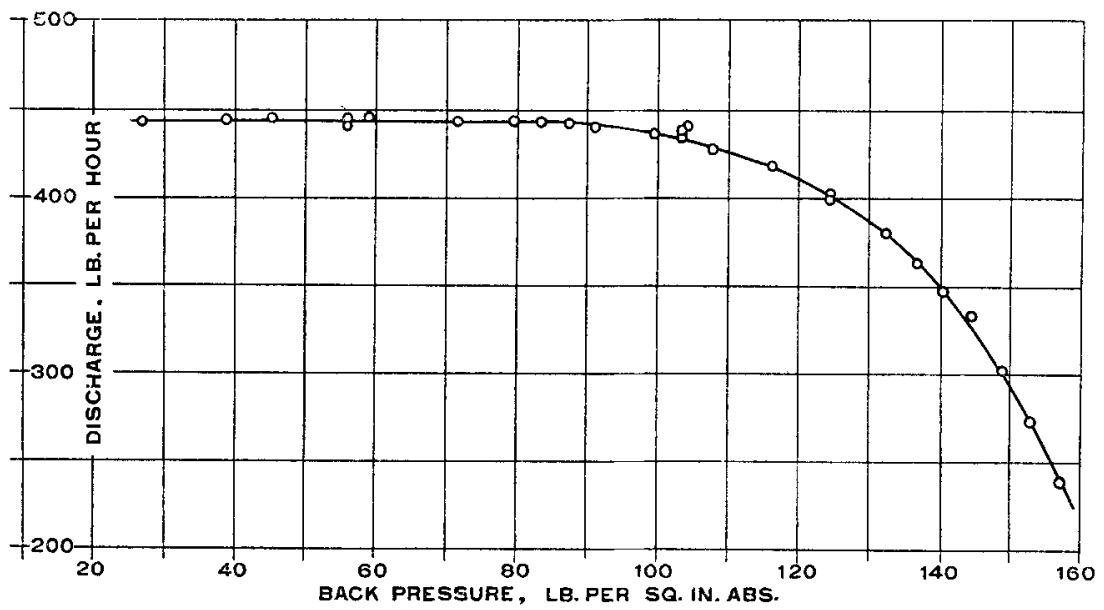

recompression in the tapering outlet, two nozzles were constructed having the curve of entry as in nozzle " $a . "$ Nozzle " $e$ " was cut off after the curve of entry, and nozzle " $f$ " after the $\frac{1}{16}$-inch parallel length. The results obtained are given in Figs. 10 and 11 and Tables 8 and 9 (pages 944-5). For both nozzles the discharge was constant for low back-pressures, and began to fall away gradually at a certain point, but without discontinuity.

With nozzle " $e$ " (without parallel part) the first lowering of the discharge took place at a pressure of about $83 \mathrm{lb}$. per square inch, which is 0.48 of the supply pressure. With nozzle " $f$ " the short 
parallel portion caused the point of change to rise to $100 \mathrm{lb}$. per square inch, or 0.58 of the supply pressure. It would appear that even in this short length some recompression took place. The coefficients of discharge of nozzles " $e$ " and " $f$ " are both unity, calculating on the exact diameters as measured by microscope cathetometer.

It should be noticed that nozzle " $e$ " differs very widely from the orifices " $c$ " and " $d$," having a very easy curve of entry. Yet in both cases the critical pressure is well below the theoretical value, assuming adiabatic expansion. For steam of about the

Fig. 11.-Nozzle "f." Supply Pressure, 172 lb. per square inch abs.

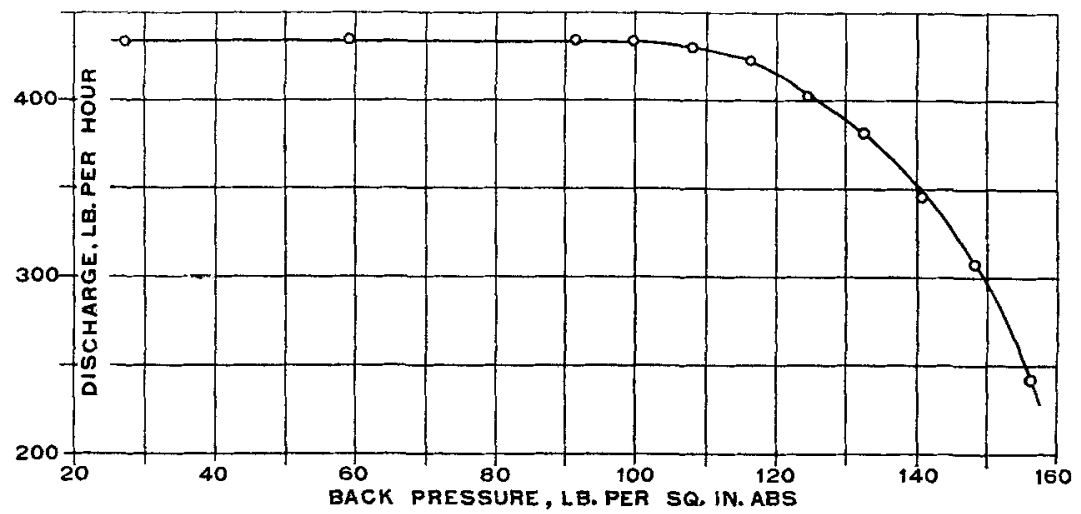

pressure and temperature used, the lower pressure for which the product of velocity and density would be a maximum in an adiabatic expansion was found by trial and plotting, using the steam tables of Marks and Davis. It was exactly 0.58 of the supply pressure.

The above experiments indicate that the critical pressure is in all cases lower than the theoretical value. Even when the backpressure for which the discharge first falls away is 0.58 of the supply pressure, there is still almost certainly a lowering of the critical pressure, the results of which are veiled by the recompression in the nozzle outlet. Such a lowering of the critical pressure could 
be caused by a steepening of the expansion line (on the pressurevolume diagram) previous to the throat. This would at the same time cause the discharges in excess of the theoretical value whirh have been recorded by many observers.

In the above experiments the discharge coefficient is in no case greater than 1. But even these discharges are surprisingly high, if one bears in mind the small size of the nozzles with the consequent importance of skin friction, and also the possibility of the stream having a true throat area smaller than the least section of the nozzle. The evidence of recompression in nozzle " $f$ " in a short parallel length, suggests the existence of such a "vena contracta."

A steepening of the expansion line, or, in other words, an increase in the index of expansion, corresponds to heat losses in the entry to the nozzle. But heat conducted away by the nozzle walls could hardly be sufficient to account for the observed fall in the critical point. The flow of energy through the $\frac{1}{4}$-inch nozzles was, at its maximum, about half a million B.Th.U. per hour, a quantity with which the heat conducted by the nozzle walls will hardly bear comparison. If the lowering of the critical pressure below the theoretical value be explained by an increase in the expansion index, some other physical cause for the disappearance of heat must be looked for.

The author is indebted to Professor F.: W. Burstall (Member) and to the University of Birmingham for facilities for experimental work; also to Messrs. A. U. Zimmerman and A. W. Hone for occasional assistance.

The Paper is illustrated by 11 Figs. in the letterpress. 
TABLE 1.-Discharge from Nozzle " a."

Supply Pressure, $172 \mathrm{lb}$. per square inch abs.

\begin{tabular}{|c|c|c|}
\hline Supply Temperature. & Back-Pressure. & Discharge. \\
\hline O F. & Lb. per square inch. & Lb. per hour. \\
$395 \cdot 2$ & $69 \cdot 0$ & 429 \\
$402 \cdot 6$ & $83 \cdot 4$ & 424 \\
$400 \cdot 4$ & $83 \cdot 5$ & 425 \\
$402 \cdot 7$ & $104 \cdot 5$ & 422 \\
$401 \cdot 4$ & $104 \cdot 5$ & $423 \cdot 5$ \\
$402 \cdot 4$ & $124 \cdot 5$ & $423 \cdot 5$ \\
$403 \cdot 6$ & $125 \cdot 3$ & 426 \\
$404 \cdot 5$ & $146 \cdot 9$ & $420 \cdot 5$ \\
$398 \cdot 1$ & $152 \cdot 9$ & 415 \\
$407 \cdot 3$ & $157 \cdot 9$ & 360 \\
$400 \cdot 3$ & $162 \cdot 1$ & 306 \\
393 & $166 \cdot 1$ & $288 \cdot 5$ \\
390 & $167 \cdot 0$ & \\
\hline
\end{tabular}

TABLE 2.-Discharge from Nozzle "a."

Supply Pressure, $110 \mathrm{lb}$. per square inch abs.

\begin{tabular}{|c|c|c|}
\hline Supply Temperature. & Back-Pressure. & Discharge. \\
\hline$\circ$ F. & Lub per square inch. & Lb. per hour. \\
366 & $75 \cdot 9$ & 269 \\
$373 \cdot 6$ & $87 \cdot 5$ & $265 \cdot 5$ \\
373 & $99 \cdot 9$ & $265 \cdot 5$ \\
$368 \cdot 3$ & $104 \cdot 0$ & 236 \\
375 & $104 \cdot 8$ & 185 \\
\hline
\end{tabular}

TABLE 3.-Discharge from Nozzle " $b . "$

Supply Pressure, $172 \mathrm{lb}$. per square inch abs.

\begin{tabular}{|c|c|c|}
\hline Supply Temperature. & Back-Pressure. & Discharge. \\
\hline \% F. & Lb. per square inch. & Lb. per hour. \\
$416 \cdot 8$ & $123 \cdot 3$ & 404 \\
$409 \cdot 7$ & $135 \cdot 3$ & 401 \\
$406 \cdot 5$ & $145 \cdot 7$ & 401 \\
405 & $155 \cdot 1$ & 397 \\
$400 \cdot 4$ & $157 \cdot 6$ & 392 \\
$402 \cdot 2$ & $160 \cdot 2$ & 371 \\
$399 \cdot 7$ & $164 \cdot 5$ & 337 \\
$396 \cdot 7$ & $167 \cdot 4$ & 289 \\
\hline
\end{tabular}




\section{TABLE 4.}

Discharge from Nozzle " b."

Supply Pressure, 110 lb. per square inch abs.

\begin{tabular}{|c|c|c|}
\hline Supply Temperature. & Back-Pressure. & Discharge. \\
\hline o F. & Lb. per square inch. & Lb. per hour. \\
375 & $77 \cdot 4$ & 262 \\
$367 \cdot 7$ & $83 \cdot 8$ & 264 \\
$373 \cdot 3$ & $87 \cdot 8$ & 263 \\
$367 \cdot 8$ & $91 \cdot 5$ & 262 \\
$382 \cdot 6$ & $97 \cdot 8$ & 259 \\
$381 \cdot 7$ & $94 \cdot 5$ & 260 \\
$379 \cdot 6$ & $100 \cdot 7$ & 258 \\
$375 \cdot 6$ & $103 \cdot 2$ & 248 \\
$374 \cdot 7$ & $104 \cdot 7$ & 224 \\
\hline
\end{tabular}

TABLE 5.-Discharge from Orifice " $\mathrm{c}$ " (1st set of Tests). Supply Pressure, $172 \mathrm{lb}$. per square inch abs.

\begin{tabular}{|c|c|c|}
\hline Supply Temperature. & Back-Pressure. & Discharge. \\
\hline $\begin{array}{l}\circ \mathrm{F} . \\
388 \cdot 1 \\
385 \cdot 9 \\
376 \cdot 8 \\
416 \cdot 6 \\
385 \cdot 6 \\
383 \cdot 4 \\
400 \cdot 9 \\
405 \\
390 \\
400 \cdot 9 \\
406 \cdot 1 \\
386 \\
388 \cdot 5 \\
389 \\
387 \cdot 5\end{array}$ & $\begin{array}{l}\text { Lb. per square inch. } \\
31 \cdot 8 \\
43 \cdot 3 \\
50 \cdot 3 \\
50 \cdot 8 \\
58 \cdot 0 \\
68 \cdot 3 \\
72 \cdot 7 \\
78 \cdot 2 \\
78 \cdot 5 \\
83 \cdot 5 \\
86 \cdot 3 \\
95 \cdot 2 \\
101 \cdot 7 \\
104 \cdot 8 \\
109 \cdot 2\end{array}$ & $\begin{array}{l}\text { Lub. per hour. } \\
367 \\
365 \\
367 \\
357 \\
362 \\
357 \\
351 \\
347 \\
359 \\
342 \\
336 \\
330 \\
327 \\
319 \\
315\end{array}$ \\
\hline
\end{tabular}


TABLE 6.-Discharge from Orifice "c" (2nd set of Tests).

Supply Pressure, $172 \mathrm{lb}$. per square inch abs.

\begin{tabular}{|c|c|c|}
\hline Supply Temperature. & Back-Pressure. & Discharge. \\
\hline $\begin{array}{l}\circ \text { F. } \\
387 \\
393 \\
396 \\
395 \\
393 \\
392 \\
396 \\
398 \\
392 \\
396 \\
383 \\
397 \\
395 \\
396 \\
391\end{array}$ & $\begin{array}{l}\text { Lb. per square inch. } \\
\qquad \begin{array}{c}34 \cdot 7 \\
42 \cdot 5 \\
50 \cdot 7 \\
63 \cdot 0 \\
71 \cdot 1 \\
79 \cdot 5 \\
83 \cdot 8 \\
87 \cdot 4 \\
91 \cdot 1 \\
95 \cdot 2 \\
102 \cdot 0 \\
103 \cdot 6 \\
112 \cdot 9 \\
116 \cdot 2 \\
120 \cdot 4\end{array}\end{array}$ & $\begin{array}{c}\text { Lb. per houx. } \\
361 \\
359 \\
355 \\
350 \\
344 \\
341 \\
335 \\
330 \\
329 \\
322 \\
318 \\
309 \\
295 \\
286 \\
278\end{array}$ \\
\hline
\end{tabular}

TABLE 7.-Discharge from Orifice " $d . "$

Supply Pressure, $172 \mathrm{lb}$. per square inch abs.

\begin{tabular}{|c|c|c|}
\hline Supply Temperature. & Back-Pressure. & Discharge. \\
\hline${ }^{\circ}$ F. & Lb. per square inch. & Lb. per hour. \\
399 & $27 \cdot 3$ & $353 \cdot 8$ \\
394 & $35 \cdot 1$ & $354 \cdot 5$ \\
390 & $47 \cdot 6$ & $353 \cdot 5$ \\
384 & $59 \cdot 3$ & $349 \cdot 5$ \\
384 & $71 \cdot 7$ & $344 \cdot 7$ \\
385 & $87 \cdot 5$ & $331 \cdot 0$ \\
388 & $91 \cdot 6$ & $327 \cdot 5$ \\
389 & $104 \cdot 5$ & $308 \cdot 0$ \\
389 & $114 \cdot 7$ & $291 \cdot 0$ \\
391 & $130 \cdot 8$ & $258 \cdot 7$ \\
386 & $136 \cdot 8$ & $246 \cdot 0$ \\
\hline
\end{tabular}


TABLE 8.-Discharge from Nozzle " $e . "$

Supply Pressure, $172 \mathrm{lb}$. per square inch abs.

\begin{tabular}{|c|c|c|}
\hline Supply Temperature. & Back-Pressure. & Discharge. \\
\hline $\begin{array}{l}\text { F. } \\
398 \\
398 \\
388 \\
396 \\
398 \\
396 \\
383 \\
383 \\
383 \\
392 \\
390 \\
389 \\
386 \\
386 \\
389 \\
390 \\
392 \\
390 \\
379 \\
386 \\
388 \\
390 \\
382 \\
382 \\
382 \\
381 \\
390 \\
388\end{array}$ & $\begin{array}{c}\text { Lb. per square inch. } \\
83 \cdot 1 \\
91 \cdot 0 \\
99 \cdot 3 \\
107 \cdot 6 \\
116 \cdot 0 \\
124 \cdot 1 \\
132 \cdot 2 \\
140 \cdot 2 \\
148 \cdot 5 \\
26 \cdot 7 \\
58 \cdot 9 \\
42 \cdot 7 \\
103 \cdot 4 \\
136 \cdot 5 \\
38 \cdot 7 \\
71 \cdot 3 \\
103 \cdot 4 \\
152 \cdot 8 \\
157 \cdot 2 \\
55 \cdot 8 \\
55 \cdot 8 \\
55 \cdot 8 \\
103 \cdot 7 \\
124 \cdot 4 \\
144 \cdot 4 \\
148 \cdot 7 \\
87 \cdot 2 \\
79 \cdot 4\end{array}$ & $\begin{array}{l}\text { Lb. per hour. } \\
443 \\
440 \\
437 \\
428 \\
418 \\
400 \\
381 \\
347 \\
302 \\
443 \\
446 \\
445 \\
439 \\
363 \\
444 \\
443 \\
435 \\
273 \\
238 \\
441 \\
441 \\
445 \\
440 \\
403 \\
333 \\
304 \\
443 \\
444\end{array}$ \\
\hline
\end{tabular}

The figures in this Table are in the order of the actual observations. The smoothness of the curve, Fig. 10 (page 988), shows that the calibration of the measuring orifice wes constant. 


\section{TABLE 9.}

Discharge from Nozzle " $f$."

Supply Pressure, $172 \mathrm{lb}$. per square inch abs.

\begin{tabular}{|c|c|c|}
\hline Supply Temperature. & Back-Prossure. & Discharge. \\
\hline${ }^{\circ}$ F. & Lb. per square inch. & Lb. per hour. \\
366 & $27 \cdot 0$ & 433 \\
366 & $59 \cdot 0$ & 434 \\
367 & $91 \cdot 3$ & 433 \\
368 & $99 \cdot 5$ & 433 \\
370 & $107 \cdot 9$ & 429 \\
366 & $116 \cdot 3$ & 422 \\
380 & $124 \cdot 4$ & 402 \\
382 & $132 \cdot 5$ & 381 \\
371 & $140 \cdot 7$ & 345 \\
374 & $148 \cdot 1$ & 2407 \\
373 & $156 \cdot 4$ & 242 \\
\hline
\end{tabular}

\section{Discussion by Correspondence.}

Mr. C. Humphrey WingField wrote that he wished to ask whether the conclusions reached with the slightly superheated steam used in these experiments would apply also to saturated steam.

He was struck by the statement (page 932 ) that an increase of superheat resulted in a diminution in the weight of steam passing, although the drop in pressure remained unaltered. On marking the experimental points with the initial pressure, as had been done in Fig. 7 (page 935), he found that the diagrams were certainly in accordance with this statement. This seemed to clash somewhat

3 т 2 
(Mr. C. Humphrey Wingfield.)

with the view generally (indeed, he believed universally) accepted, that if a certain drop of pressure took place between a boiler and an engine using saturated steam, the velocity might be very considerably increased if the steam were superheated before the loss of head had reached its previous extent. With fairly high superheat, the velocity might be 50 per cent. more than with saturated steam. The increase in volume due to superheating was often roughly taken as $12 \frac{1}{2}$ per cent. for each 100 degrees of superheat. Evidently a much greater temperature than that actually used must be attained before the velocity even approached an increase of 50 per cent., if the weight passing per second remained unaltered. He would therefore expect an increased flow with increased temperature.

Could the author put his results in a form from which the relative sizes of orifices, necessary to pass a given weight of steam per second at a definite pressure, could be read off for the two cases of saturated and slightly superheated steam; the condition of equal drop of pressure to be allowed for? This might be useful in the design of valves.

On page 929 a circular drowned weir was mentioned. Was a correction made for the varying temperature of the water and for the consequent alteration in viscosity? Mr. Mair-Rumley's experiments showed that the effect of temperature on the coefficient of resistance in pipes was not negligible, except for the large apertures he tried. Was this so with small orifices as well?

An expanding nozzle was often used with centrifugal pumps and mine fans in order to increase the discharge, and the "ancients" used to swindle waterworks inspectors by attaching expanding nozzles to the parallel jets of which they had just gauged the rate of delivery, thus obtaining more water than was booked against them. There was undoubtedly a greater flow in these instances than without expanding orifices.

The author seemed to have found the reverse to be true with his nozzles. Fig. 10 (page 938) showed a maximum flow of about $445 \mathrm{lb}$. per hour with nozzle " $e$ "; Fig. 11 showed about $435 \mathrm{lb}$. per hour when a short parallel portion was added, and Fig. 3 (page 931) showed 
only about $425 \mathrm{lb}$. per hour when an expanding orifice was attached. How did the author account for these discrepancies? His experiments seemed to give results contrary to daily experience, and therefore the writer did not feel satisfied that the nozzles could be taken as generally representative of what might be expected when the proportions and conditions were more favourable.

The author's statement (page 938) that small changes in the nature of the edges of orifices produced big results was confirmed by some experiments which had been published on the flow of water through round orifices in thin brass plates. These were tested first with the flow in one direction, and secondly, with the plates turned round so as to reverse the flow. It was found that it was practically impossible to get the same results from both sides, although very great care was taken to finish the holes accurately and without wire-edges.

If the author could explain the seemingly wide departures of his experimental results from those ordinarily accepted, his Psper, which evidently represented a vast amount of careful work, would no doubt be useful, but otherwise its scope would seem to be limited to the particular nozzles tested.

Dr. Fisher wrote, in reply to Mr. Wingfield's Communication, that the superheat used in the experiments described was not high, and the results generally should apply to saturated steam. Experiments with superheat were preferable to those on saturated steam, as the thermometer and pressure-gauge readings gave complete information. In the case of steam expanding in a nozzle, the available energy per pound, and in consequence the throat velocity, were not much increased by superheating the supply. But the density was considerably reduced, with the consequence that the mass discharge fell away as the degree of superheat increased. This result was verified in a number of unpublished experiments. For parallel flow in a long pipe, viscosity would probably be the main factor fixing the pressure drop for a given velocity.

With regard to the orifice method of measuring water flow, a correction for temperature was necessary (page 929). Temperature 
(Dr. Fisher.)

affected both the density and viscosity of the water, and also the density of the gauge-glass column used to indicate the pressure at the orifice; a calibration of the actual apparatus would usually be best.

The three nozzles with similar inlets were independent and not obtained by cutting down the long one. In consequence their diameters were not exactly the same. The discharge coefficient was in each case unity (page 939). 